\title{
Localized Blistering Eruption of the Face and Neck- A Case Study and Differential Considerations
}

\author{
Małgorzata Michalska-Jakubus', Anita Wdowiak-Filip ${ }^{2}$, Cezary Kowalewski ${ }^{3}$, Katarzyna Woźniak ${ }^{3}$, \\ Dorota Krasowska' \\ 'Department of Dermatology, Venereology and Pediatric Dermatology, Medical University of Lublin, Lublin, Poland; ${ }^{2}$ Department of Cosmetology and \\ Aesthetic Medicine, Medical University of Lublin, Lublin, Poland; ${ }^{3}$ Department of Dermatology, Immunodermatology and Venereology, Medical \\ University of Warsaw, Warsaw, Poland \\ Correspondence: Anita Wdowiak-Filip, Staszica II, Lublin, 20-08I, Poland, Tel +48 7986475 07, Email anita.wdowiak@gmail.com
}

\begin{abstract}
We describe a 36-year-old woman with erythematous lesions and well-tense blisters confined to the face and neck of two months history, without mucosal involvement and no triggering factors. A lesional skin biopsy showed a subepidermal blister. Direct immunofluorescence of peribullous skin identified linear deposits of $\mathrm{IgG}, \mathrm{IgA}$, and C3 complement along the basement membrane zone, whereas indirect immunofluorescence was negative. Using fluorescence overlay antigen mapping by laser scanning confocal microscopy, linear immunoglobulins deposits were found to be located above collagen IV and below laminin 332 (formerly named laminin 5), in a pattern typical of mucous membrane pemphigoid (formerly named cicatricial pemphigoid). Consequently, in terms of the clinical picture and confocal study, a rare variant of mucous membrane pemphigoid was established, namely Brunsting-Perry type. Combined therapy with oral prednisone and dapsone healed the lesions, leaving atrophic scars and milia. The paper also provides a review of previous reports on this item as well as a comprehensive differential diagnosis of facial blistering lesions.
\end{abstract}

Keywords: mucous membrane pemphigoid, Brunsting-Perry pemphigoid, laser scanning confocal microscopy

\section{Introduction}

Mucous membrane pemphigoid (MMP) is an autoimmune inflammatory disorder characterized by blistering lesions of mucous membranes and skin. ${ }^{1}$ In classic MMP, oral mucosa and conjunctiva are typically affected and may cause significant dysfunction, including blindness. ${ }^{2,3}$ Skin involvement is observed in 25-35\% of MMP patients with welltense blisters localized mainly on the head, neck, and upper torso that heal, leaving atrophic scars and milia. ${ }^{1,4,5}$ They result from subepidermal split without acantholysis accompanied by mixed-cell infiltrates of lymphocytes, plasmacytes, histiocytes, neutrophils, and eosinophils. ${ }^{5}$ The exact etiopathogenesis is still poorly understood but associated with autoantibodies against basement membrane zone (BMZ) proteins that are mirrored by linear deposition of immunoglobulin $\mathrm{G}, \mathrm{A}$, or complement $\mathrm{C} 3$ along the basement membrane. The main target antigens are bullous pemphigoid antigen $180 \mathrm{kDa}(\mathrm{BP} 180)$ and laminin 332 (laminin 5). ${ }^{4,6}$

The clinical presentation of MMP is very diverse and may cause diagnostic difficulties. In the literature, there are scarce reports of rare type of MMP confined to the skin, termed Brunsting-Perry type (MMP-BP). This type of pemphigoid has histopathologic and immunofluorescence microscopic features similar to those observed in MMP; however, mucous membranes are generally spared. It may also mimic other vesiculobullous diseases, such as bullous pemphigoid (BP), epidermolysis bullosa acquisita (EBA), dermatitis herpetiformis (DH), linear IgA bullous dermatosis (LABD) or bullous systemic lupus erythematosus (BSLE), as well as impetigo. ${ }^{7}$ Since MMP-BP is also heterogeneous in terms of immunological findings, it may be a real diagnostic challenge.

Herein, we present the case of Brunsting-Perry MMP in a 36-year-old female with negative indirect immunofluorescence and diagnosis established using fluorescence overlay antigen mapping by laser scanning confocal microscopy (FOAM-LSCM). 
Additionally, we provide a review of previously reported data on MMP-BP in terms of clinical, immunological, and therapeutic aspects as well as a comprehensive differential diagnosis of facial blistering diseases.

\section{Case Presentation}

A 36-year-old woman with a 2-month history of pruritic, vesiculobullous eruption located on her face and neck has been admitted to the Department of Dermatology in November 2020 for diagnosing. In outpatient settings, the patient was treated with topical steroids without clinical effect. Initial physical examination revealed numerous, well-tense blisters and erosions arranged in a herpetiform pattern at the margins of well-outlined oval or polycyclic erythematous and slightly atrophic plaques located in the central zone of the face, left cheek, and mandibular area. Blisters varied in size with the largest less than $1 \mathrm{~cm}$ in diameter (Figure 1A). Additionally, a few similar lesions were scattered over the frontal portion of the patient's neck and upper back (Figure 1B). The blistering plaques enlarged slowly peripherally and healed with slightly atrophic scars and milia (Figure 1C). The patient complained about pruritus and burning of the lesional skin. Other areas of the skin were not affected, and no mucosal involvement was found.

The patient was in good general health without any chronic disorder, pharmacological therapy, or supplements intake. Her family history was negative for either vesiculobullous or other autoimmune diseases, and the condition was not affected by sunlight exposure. No other evident triggering factor was found.

Reports of routine laboratory tests were of normal values. In the blood, eosinophils constituted $5.4 \%$ of total white blood cells. Antinuclear antibodies (ANA), extractable nuclear antigens (ENA), double-stranded DNA (dsDNA), and anti-transglutaminase-1 (TG1) antibodies were all negative. Neither bacterial nor fungal growth was found in the lesional smear. UVA testing was negative, but MED-UVB was $0.03 \mathrm{~J} / \mathrm{cm}^{2}$. The Tzanck test showed a trace of protein masses, neutrophils, and eosinophils but no acantholytic cells.

Microscopic examination of a lesional skin biopsy showed a subepidermal blister filled with proteinaceous fluid and neutrophils without acantholysis. Intensive inflammatory infiltration was present under the epithelium and around vessels composed of plasma cells, lymphocytes, and eosinophils.
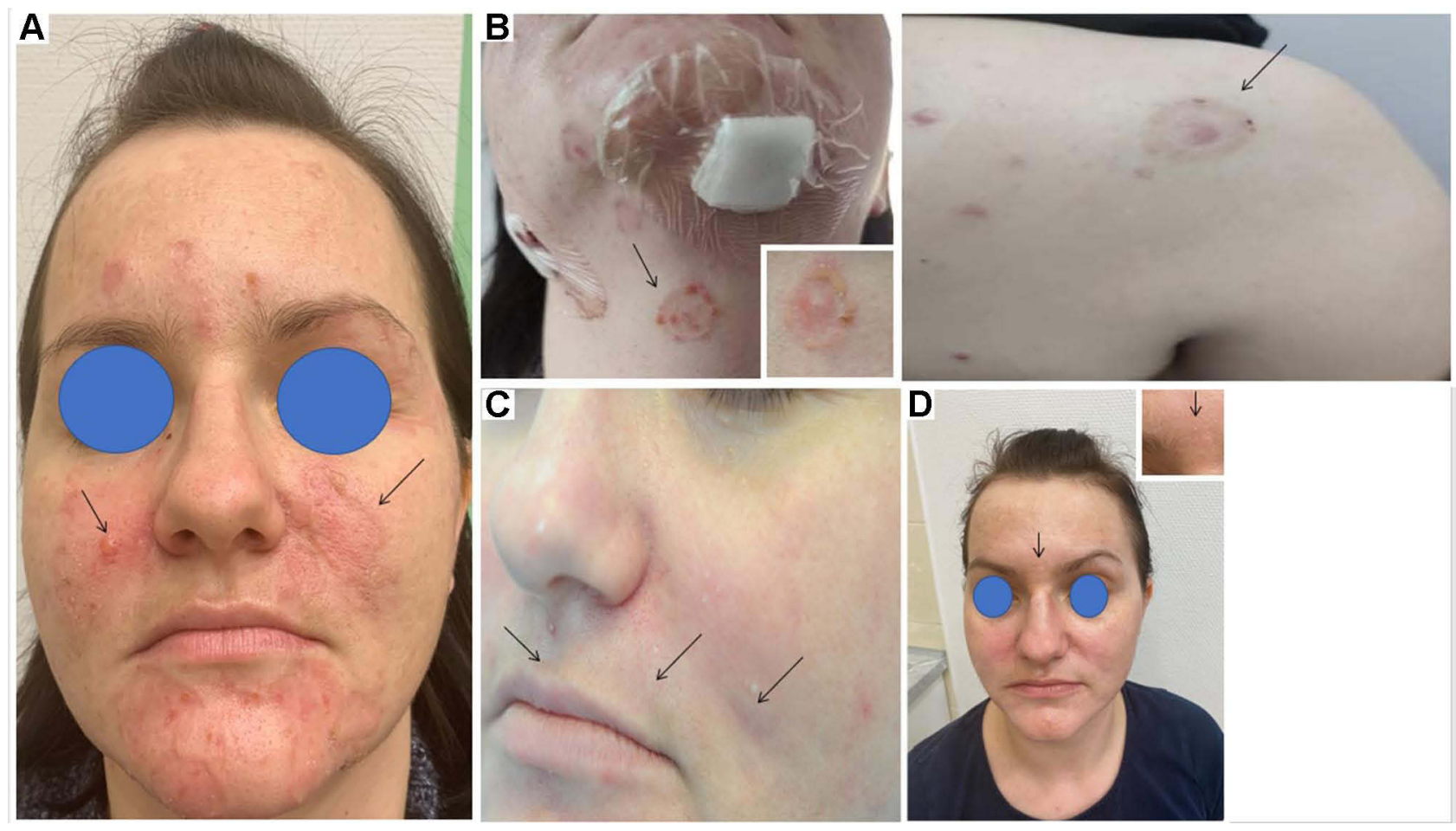

Figure I (A) Before treatment: polycyclic erythematous and slightly atrophic plaques located in the central zone of the face; (B) well-tense blisters and erosions arranged in a herpetiform pattern on the frontal portion of patient's neck and upper back; (C) One month after I pulse of intravenous methyloprednizolon: slightly atrophic scars, hypopigmentation and sparse milia; (D) 6 months after dapsone and prednison treatment: a few milia and slightly anthropic scars, no new blisters. 
Direct immunofluorescence (DIF) study of peribullous skin demonstrated linear deposits of IgG, IgA as well as complement $\mathrm{C} 3$ fraction with a moderate intensity along the dermoepidermal junction. However, routine and on a saltsplit skin indirect immunofluorescence (IIF) were negative for circulating antibodies against BMZ antigens. Dermatology Profile ELISA (IgG) by EUROIMMUNE for 6 antigens (BP180, BP230, Dsg1, Dsg3, Envoplakin, Collagen type VII) was also negative.

To precise the diagnosis, the patient was referred to the Section of Immunopathology of Laboratory of Skin Diseases in Warsaw, where FOAM-LSCM study disclosed the presence of IgG deposits within the BMZ located below laminin 332 and above collagen IV in a pattern typical for MMP (Figure 2A and B). Based on the clinical picture of vesiculobullous eruption confined to the skin of upper body area without mucosal involvement and the result of FOAM-LSCM examination the diagnosis of Brunsting-Perry type of MMP was established.

The patient was treated with prednisone (in the initial dose of $30 \mathrm{mg} /$ day with a gradual reduction to $5 \mathrm{mg} / \mathrm{day}$ as the condition improved) along with dapsone (50 mg/day with a periodic dose reduction to $50 \mathrm{mg} / \mathrm{every}$ other day due to the increase in methemoglobin value) with a good therapeutic response. Blistering and erosions subsided gradually, leaving slightly atrophic scars, hypopigmentation, and sparse milia (Figure 1C and D). The pruritus was relieved. During the follow-up period, the patient remained free of active cutaneous lesions and the ocular, as well as oral mucous membranes had remained free of involvement.

\section{Discussion}

Clinics of BP-MMP (also called localized cicatricial pemphigoid) was originally described in 1957 based on 7 cases of patients with recurrent vesiculobullous herpetiform eruption localized predominantly on the head, neck, and upper trunk, which were healing with atrophic scars. ${ }^{8}$ In that primary report, small pruritic vesicles in other skin areas (eg, volar aspects of the wrist), urticarial reactions, and exacerbation resembling dermatitis herpetiformis appeared occasionally in some patients. Microscopically, the bullae were subepidermal. ${ }^{8}$ Hence, single cases or case series of the BP-MMP were outlined by several authors. Among others, in 1966 MacVicar and Graham described 10 similar cases and suggested the name "localized chronic pemphigoid". 9 However, the data on the number of reported cases is ambiguous, ranging from 43 (Leenutaphong et al, 1989) to 27 (Osipowicz et al, 2019). ${ }^{10,11}$ The discrepancy may be justified since some of these cases were published before the era of immunodermatology and thus not confirmed in terms of in vivo bound immunoglobulins or target antigens. Pioneer immunofluorescent study of BP-MMP was reported by Michel et al in 1977. ${ }^{12}$ Therefore, some patients could be incorrectly classified as the proper Brunsting Perry CP instead of bullous pemphigoid (BP), epidermolysis bullosa acquisita (EBA), or mucous membrane pemphigoid (MMP) which present clinical similarities. ${ }^{13}$ Recently, the largest case series of twelve BP-MMP patients has been reported by Imstepf et al, but the diagnosis was based only on routine DIF thus may not be reliably confirmed. ${ }^{14}$

Data obtained from those reports showed that BP-MMP is most common for middle-aged individuals (age of 50-60) with 75-98\% patients older than 50 years and a slight male predominance (55-63\%). ${ }^{10,11,15}$ All reported cases, including ours, had typical involvement of the head and/or upper trunk, except one published by Iranzo et al but 6 out of $26(23 \%)$

A

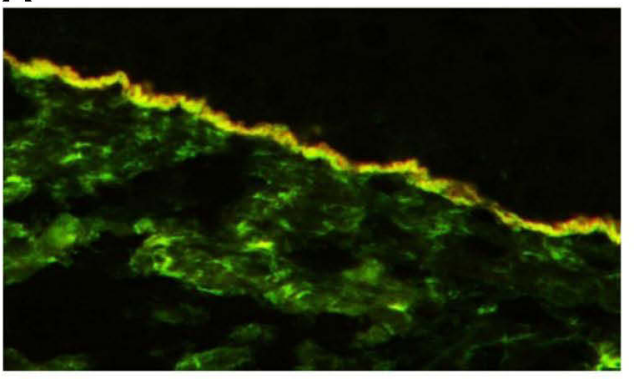

B

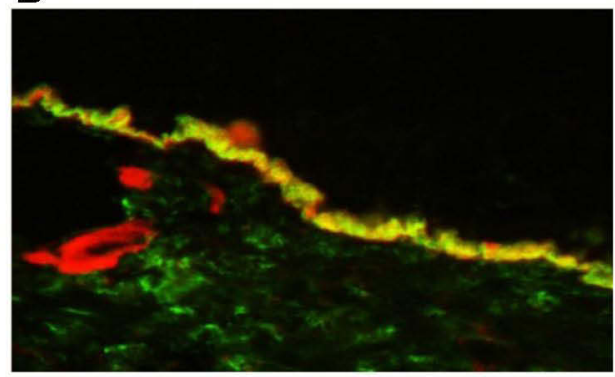

Figure 2 Fluorescence overlay antigen mapping by laser scanning confocal microscopy (FOAM-LSCM) study: (A) linear IgG deposits (green color) localized below laminin332 (red color); (B) linear IgG deposits (green color) localized above collagen IV (red color) at the basement membrane zone (BZM) characteristic of mucous membrane pemphigoid. 
or 18 out of $43(42 \%)$ reviewed patients also presented lesions in other skin areas. ${ }^{8}{ }^{11,16}$ In almost all cases, scarring of resolving lesions was observed, and active blistering was recurrent over a period ranging from 1 to 25 years. ${ }^{8}$ If the scalp was involved, scarring alopecia occurred. ${ }^{15,17,18}$ Pruritus of the lesional skin was the most common, but not a regular symptom of the disease, reported in over $80 \%$ of BPMMP patients. ${ }^{8}$ Moreover, sparse milia within atrophic scars can be observed in the lesional sites. ${ }^{4,8,19}$ Confusingly, up to $20 \%$ of reported patients had oral mucous membranes affected, including one case in the original description by Brunsting and Perry, or even scarring conjunctivitis, indicating that at least some of them may have been misclassified as BP-MMP although fulfilling clinical criteria of MMP. ${ }^{8,11,13}$ Factors, such as sun exposure, drug-induced cutaneous photosensitivity (with furosemide), stress, excitement, anger, fatigue, and overwork have been noted to provoke new outbreaks in some patients (12). Dipeptidyl peptidase 4 (DPP-4) inhibitors and sartans may also be potential trigger. ${ }^{14}$ Moreover, ingestion of certain dietary items, particularly pork products and eggs were suspected to aggravate the condition. ${ }^{8,20}$ The history of atopy has been found in a minority of cases. ${ }^{8,12}$ In the histopathological examination, apart from the invariable subepidermal location of the blister, perivascular infiltrates composed largely of small mononuclear cells with some eosinophils in the papillary dermis are observed, although in the original description, cellular reaction was predominantly eosinophilic. ${ }^{8,10,11}$ However, similar features may be observed in BP, therefore histopathology cannot be the base of diagnosis. In the great majority of BP-MMP cases, DIF shows linear depositions of $\mathrm{IgG}$ (and in some cases IgA) along the BMZ, while C3 complement deposits are detected in about $50 \%$ of cases similar to typical MMP and EBA. ${ }^{11,21}$ DIF-negative cases have also been reported. ${ }^{10}$

The presented case had the typical clinical features of Brunsting-Perry MMP with great similarity to that originally described by Brunsting and Perry in terms of morphology and arrangement of blisters, and atrophic plaques on the upper part of the body, as well as itching that was the most distressing symptom. Of note, in our patient, lesions were not present in other skin regions, no urticarial reaction was observed, and importantly no mucous membranes were affected. There was also no apparent triggering or exacerbating factor. It is also worth noting that our 36-year-old female case ranks in $25 \%$ of all cases (ie, younger than 50 years old). Only four younger patients with BPMMP, aged 20-33 years old, were described so far, including two males [M] and two females [F] [Sugita (2001) F/33, Minato (2011) M/31, SatoShibuya (2016) F/20, Person (1976) M/29]. ${ }^{6,22-24}$

Although, quite well-characterized, clinical picture of BPMMP may be similar to other vesiculobullous diseases, such as bullous pemphigoid (BP), epidermolysis bullosa acquisita (EBA), dermatitis herpetiformis (DH), linear IgA dermatosis (LAD), or bullous systemic lupus erythematosus (BSLE). ${ }^{7,11,21}$ They all belong to the group of autoimmune subepidermal bullous diseases (ASBDs; or subepidermal immune bullous diseases, SIBD) that may mimic each other not only clinically, but they are all characterized by the presence of circulating antibodies against different BMZ antigens as well as the presence of linear immunoglobulins and complement deposits at the dermo-epidermal junction with the except of DH where granular IgA deposits are found in the dermal papillae. Thus, routine DIF examinations cannot reliably differentiate them and may result in misdiagnosis. ${ }^{11,21,23}$

In particular, distinguishing BPMMP from EBA, mainly localized form of EBA, can be challenging, as was shown by Wozniak et al several years ago, but is of great interest due to different clinical behavior, therapy and prognosis.

In patients with detectable circulating antibodies, techniques such as immunoblotting, radioimmunoprecipitation or ELISA may be helpful in the diagnosis based on antibodies specificity. In EBA circulating antibodies react with type VII collagen of anchoring fibrils with a dermal pattern on salt-split skin IF (binding to the floor of the blister), whereas in MMP they are mainly, but not exclusively, directed to the carboxyterminal end of BP180 antigen, and in 50-80\% of cases produce linear deposits on either epidermal or the dermal side of splitted skin. ${ }^{3,25,26}$ BPMMP is even more heterogeneous in terms of immunological findings and circulating antibodies, if detectable, recognize different BMZ antigens. ${ }^{11,23,26}$ The main identified target antigen was BP180 (or specifically NC16a domain of BP180) localized in the upper part of lamina lucida and characteristic of bullous pemphigoid, laminin 332 (laminin 5, formerly epiligrin) localized in the upper part of lamina densa and characteristic of anti-epiligrin cicatricial pemphigoid, and carboxyterminal end of BP180 at the lamina lucida-lamina densa border characteristic of MMP. Single cases associated with other target antigens have also been described (Table 1). Subsequently, immunoglobulins deposits can be variously located with respect to the split level of human skin using salt-split technique based on IIF microscopy and may not eventually be distinguishable. ${ }^{11,26}$ Differential diagnosis is additionally complicated by the fact that in some patients with BPMMP, antibodies to type 
VII collagen, localized in the lower lamina densa and sub-lamina densa have been described which are typical for EBA. $^{3,6,10,21,23,28}$ Consequently, some authors have suggested that Brunsting-Perry CP may represent a clinical, localized variant of $\mathrm{EBA}^{3,28-32}$. In the study by Joly et al the patient had the typical clinical features of Brunsting-Perry MMP, however DIF studies on salt-split peribullous skin showed IgG and C3 deposits located exclusively on the floor and not on the roof of the blister in a pattern usually found in patients with EBA. The dermal location of the autoantibodies was confirmed by direct IEM that showed dermal cleavage level below the lamina densa, and IgG and C3 deposits within and below the LD, which is also identical to EBA. ${ }^{29}$ Moreover, circulating antibodies are detectable in less than $50 \%$ of BPMMP cases or even in less than $20 \%$ of cases when using IIF. ${ }^{10,11}$ Similarly, circulating antibodies are rarely detectable in MMP and EBA cases (20\% and 50\%, respectively). ${ }^{13,21}$ It was also a concern in the presented case of BPMMP (IIF was twice negative in two different laboratories, as well as was ELISA), so we were unable to characterize the target antigen.

In patients with ASBDs in whom circulating anti-BMZ antibodies are not detectable, direct immunoelectron microscopy (IEM) or, more recently, fluorescence overlay antigen mapping with laser scanning confocal microscopy (FOAM-LSCM) has been found to be crucial for differentiating autoimmune subepidermal blistering disorders. ${ }^{10,11,21,32,33}$ Application of LSCM in a case with clinical features of BPMMP was first outlined in 2019 by Osipowicz et al, and the diagnosis obtained by this technique was confirmed by immunoblot results. ${ }^{11}$ Similarly, to the original study, both IgG and IgA, as well as C3 complement located below laminin-332 and above type IV collagen were disclosed by FOAM-LCSM in our patient, which is characteristic of MMP with autoantibodies directed against the C-terminal portion of BP180 antigen. ${ }^{11}$ This makes our case even more interesting, as only two documented cases of BPMMP with IgG autoantibodies to the C-terminal portion of BP180 were reported so far. ${ }^{11,27}$ In contrast, in BP IgG deposits are located above laminin 332, and in EBA below type IV collagen. ${ }^{11,21,32}$

Another possible diagnosis of our case was anti-epiligrin MMP. However, all of the reported cases of antiepiligrin (anti-laminin 332) MMP had mucosal lesions, unlike our case who tended toward mucosal sparring like Brunsting-Perry MMP, and LCSM pattern was exclusive. ${ }^{34}$

Systemic bullous lupus erythematosus (BSLE) should also be considered in the differential diagnosis of BPCP BSLE is an uncommon type of SLE. ${ }^{35}$ Blisters and vesicles are approximately less than $1 \%$ of all cutaneous lesions seen in SLE. BSLE is characterized by subepidermal, tense vesiculobullous eruptions located in any area of the body. In BSLE, main autoantibodies are anti-type VII collagen antibodies, antibodies against laminin 332 or 331, and BP antigen-230 $\mathrm{kDa}$. Thus, on routine DIF examination, it produces linear a pattern along BMZ the same as in BPCP, but IIF on salt-split skin usually demonstrates IgG deposits on the dermal side (floor pattern) of the blister-like in EBA, not on the epidermal side (roof pattern) like in pemphigoid, except cases with anti-BP230 antibodies ${ }^{11 .}$ In the presented case BSLE could also be considered due to morphology of skin lesions, involvement of sun-exposed skin areas, positive MED-UVB test and location of immunoglobulins deposits at the dermo-epidermal junction on routine DIF. However, negative salt-split skin IIF EUROIMMUNE-ELISA, ANA, mucosal sparing, lack of other clinical or laboratory criteria of American College of Rheumatology (ACR) for SLE, and finally result of LSCM study ruled out this diagnosis. Of note, the major clinical difference was that all the reported cases of BSLE showed generalized instead of the localized bullous eruption as the initial skin manifestation. ${ }^{30}$

Linear IgA dermatosis (LAD) is also a subepidermal autoimmune bullous disorder that may present a similar annular pattern of skin blistering with scarring and milia formation, and the face is one of the predisposed areas of involvement. ${ }^{20}$ However, in contrast to BPMMP, in $80 \%$ of patients' lesions also appear on the mucous membranes and periorificial location (mouth, genital region) is common. ${ }^{5,36-38}$ There are, also, clear differences in the histopathological examination, including microabscesses in the skin papillae and in routine DIF linear IgA deposits along the dermal-epidermal junction that enable clear diagnosis of LAD. ${ }^{5,36}$

We summarized the differential diagnosis of facial localized bullous eruptions in Table 1.

Accurate diagnosis of cases with the localized blistering eruption of the face is highly requisite mainly due to differences in the course, prognosis, and response to treatment. Patients with BP usually had a good prognosis and required rather mild therapy. In contrast, in the case of MMP and EBA, early diagnosis and aggressive 
Table I Differentiation Between Brunsting-Perry CP, MMP, BP, EBA, LAD, BSLE

\begin{tabular}{|c|c|c|c|c|c|c|}
\hline & BP CP & MMP & BP & EBA & LAD & BSLE \\
\hline $\begin{array}{l}\text { Clinical } \\
\text { features }\end{array}$ & $\begin{array}{l}\text { Recurrent, itchy } \\
\text { blisters located on } \\
\text { the head, neck, } \\
\text { scalp, upper trunk } \\
\text { without mucosal } \\
\text { involvement, leaving } \\
\text { with atrophic scars } \\
\text { and milia'l }\end{array}$ & $\begin{array}{l}\text { Blistering lesions on } \\
\text { mucous membrane } \\
\text { limited to oral mucosa, } \\
\text { conjunctiva, nostrils, } \\
\text { esophagus, trachea, } \\
\text { genitals, rare skin } \\
\text { involvement, leaving } \\
\text { with anthropic scars }\end{array}$ & $\begin{array}{l}\text { Tense blisters of variable size } \\
\text { typically filled with a clear fluid } \\
\text { or blood, over urticaria-like } \\
\text { plaques or normal skin, on the } \\
\text { trunk and flexor surface of the } \\
\text { extremities, accompanied by } \\
\text { intense pruritus, mucosal } \\
\text { involvement in } 25 \% \text { of cases, } \\
\text { mainly oral cavity, rarely affect } \\
\text { the head or neck; no scarring } \\
\text { but postinflammatory } \\
\text { hyperpigmentation; more } \\
\text { common in elderly patients }\end{array}$ & $\begin{array}{l}\text { The classical/mechano-bullous } \\
\text { form; the non-classical/non- } \\
\text { mechano-bullous forms, } \\
\text { including: BP-like EBA with } \\
\text { clinical criteria of both EBA } \\
\text { and BP, MM-EBA clinically } \\
\text { defined by predominant } \\
\text { mucous membrane lesions, } \\
\text { lgA-EBA defined by the IgA } \\
\text { class of immune deposits, and } \\
\text { Brunsting-Perry-like EBA; } \\
\text { regardless of the clinical form: } \\
\text { muco-cutaneous fragility, with } \\
\text { lesions on trauma-prone sites } \\
\text { (typically on extensor } \\
\text { surfaces), linear pattern or } \\
\text { angular contours of bullous } \\
\text { lesions or erosions; atrophic } \\
\text { scarring, milia; clinical variants } \\
\text { confined to the face were } \\
\text { described }\end{array}$ & $\begin{array}{l}\text { Annular pattern of skin } \\
\text { blistering with scarring and } \\
\text { milia formation, skin and } \\
\text { mucous membrane; most } \\
\text { common on flexor surfaces, } \\
\text { trunk and face; periorificial } \\
\text { location (mouth, perineum) is } \\
\text { common; most common in } \\
\text { children and middle-aged } \\
\text { persons } \\
36,43\end{array}$ & $\begin{array}{l}\text { Tense bullae, on the } \\
\text { erythemato- edematous } \\
\text { plaques or normal skin, } \\
\text { involves both sun exposed and } \\
\text { nonexposed areas, non- } \\
\text { scarring, classically without } \\
\text { milia; oral mucosal } \\
\text { involvement; patients meet } \\
\text { EULAR/ACR or SLICC } \\
\text { classification criteria for } \mathrm{SLE}^{7}\end{array}$ \\
\hline
\end{tabular}




\begin{tabular}{|c|c|c|c|c|c|c|}
\hline Histology & $\begin{array}{l}\text { Subepidermal } \\
\text { blisters containing } \\
\text { neutrophils, } \\
\text { eosinophils and } \\
\text { lymphoid cells" }\end{array}$ & $\begin{array}{l}\text { Subepidermal blisters, } \\
\text { inflammatory infiltration } \\
\text { with plasma cells, } \\
\text { sometimes mast cell in } \\
\text { conjunctiva }^{21}\end{array}$ & $\begin{array}{l}\text { Eosinophilic spongiosis in early } \\
\text { or prebullous lesions; } \\
\text { Subepidermal blister with a } \\
\text { mixed superficial perivascular } \\
\text { inflammatory infiltrate with } \\
\text { abundant eosinophils }\end{array}$ & $\begin{array}{l}\text { Initially, papillary oedema and } \\
\text { vacuolar alteration along the } \\
\text { dermo-epidermal junction; a } \\
\text { subepidermal or subepithelial } \\
\text { blister at the later stage; a } \\
\text { great variability in the intensity } \\
\text { and/or composition of the } \\
\text { inflammatory infiltrate: }{ }^{41} \\
\text { Classical (non-inflammatory) - } \\
\text { sparse mononuclear cell } \\
\text { infiltrate Inflammatory- mixed, } \\
\text { neutrophilic infiltrate }\end{array}$ & $\begin{array}{l}\text { Subepidermal blisters, } \\
\text { accumulation of neutrophils in } \\
\text { a linear array at the } \\
\text { dermoepidermal junction; } \\
\text { neutrophilic microabscesses in } \\
\text { dermal papillae } 37,43\end{array}$ & $\begin{array}{l}\text { Acute interface dermatitis } \\
\text { with vacuolar degeneration of } \\
\text { the basal layer keratinocytes; } \\
\text { Subepidermal blistering with } \\
\text { dermal edema and } \\
\text { perivascular inflammatory } \\
\text { infiltrate in the superficial and } \\
\text { middle dermis; a } \\
\text { predominance of neutrophils } \\
\text { in the upper dermis with } \\
\text { microabscesses concentrated } \\
\text { within dermal papillae; large } \\
\text { deposits of mucin in the } \\
\text { reticular dermis (a } \\
\text { distinguishing feature of } \\
\text { BSLE), }\end{array}$ \\
\hline DIF & $\begin{array}{l}\text { Linear deposit of } \\
\lg G, C 3 \text {, IgA (rare) } \\
\text { along BMZ" }\end{array}$ & $\begin{array}{l}\text { Linear deposit of IgG, } \\
\text { IgA, } C 3 \text { along } B M Z^{21}\end{array}$ & $\begin{array}{l}\text { Linear deposit along BMZ, of } \\
\text { IgG and C3; C3 deposits are } \\
\text { generally more intense than } \\
\text { IgG (a predominance of IgG } \\
\text { deposit intensity may suggest } \\
\text { other sAIBD such as EBA); in } \\
\text { small percentage of cases C3 } \\
\text { deposits only; less intense } \\
\text { deposits of IgA or IgM may be } \\
\text { present; }{ }^{25}\end{array}$ & 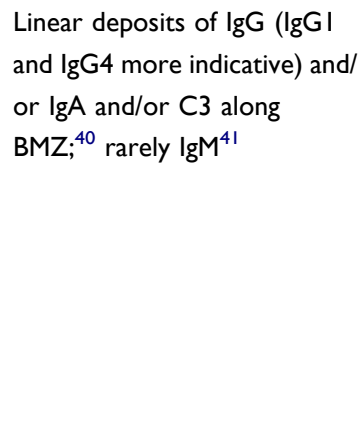 & $\begin{array}{l}\text { Linear or linear/granular (less } \\
\text { common) IgA deposits along } \\
\text { BMZ }^{36,37,43}\end{array}$ & $\begin{array}{l}\text { Linear deposits along } B M Z \text {, } \\
\lg G \text { (mainly } \lg G 2 \text { and } \lg G 3 \text { ) is } \\
\text { found most frequently, } \\
\text { followed by } \lg A \text { and } \lg M \\
\text { (lesional as well as uninvolved } \\
\text { skin); C3 almost exclusively in } \\
\text { perilesional Tissue } 7.42\end{array}$ \\
\hline IIF/split skin & $\begin{array}{l}\text { Floor pattern; mixed } \\
\text { roof and floor } \\
\text { pattern } \\
11,21\end{array}$ & Floor pattern ${ }^{|1,2|}$ & Roof pattern ${ }^{11,21}$ & Floor pattern ${ }^{40,41}$ & $\begin{array}{l}\text { Roof pattern - lamina lucida } \\
\text { subtype of LABD; floor } \\
\text { pattern (rare) - sub-lamina } \\
\text { densa variant of LAD; mixed } \\
\text { pattern } \\
36,37,43\end{array}$ & $\begin{array}{l}\text { Floor pattern; staining of the } \\
\text { keratinocyte nuclei may be } \\
\text { present (positive in vivo } \\
\text { ANA) }{ }^{7}\end{array}$ \\
\hline
\end{tabular}

(Continued) 
Table I (Continued)

\begin{tabular}{|c|c|c|c|c|c|c|}
\hline & BP CP & MMP & BP & EBA & LAD & BSLE \\
\hline $\begin{array}{l}\text { ELISA/ } \\
\text { Immunoblot }\end{array}$ & $\begin{array}{l}\text { NCI6a of BPI80, } \\
\text { BP230, C-terminal } \\
\text { portion of BPI80, } \\
\text { laminin-332, LAD-I, } \\
\text { collagen type VII, } \\
\text { desmoplakins I/ } \\
\|^{11,21}\end{array}$ & $\begin{array}{l}\text { Collagen type XVII, } \\
\text { collagen type VII, laminin } \\
332 \text {, alfa-6, beta- } 4 \\
\text { integrin subunits, I20- } \\
\text { kDa undefined epithelial } \\
\text { antigen }^{21}\end{array}$ & $\mathrm{NCI}$ 6A, BP230 27 & $\begin{array}{l}\mathrm{NCI} \text { domain of collagen VII; } \\
\text { less common: C-terminal NC2 } \\
\text { domain; laminin-332, p200 } \\
\text { protein; laminin } \gamma 1^{40}\end{array}$ & $\begin{array}{l}\text { IgA anti-basement membrane } \\
\text { zone antibodies directed } \\
\text { against the } 97 \mathrm{kDa} \text { within } \\
\mathrm{NCI} \text { (6A 2; LAD-I; collagen } \\
\text { type VII (the sub-lamina densa } \\
\text { variant of LAD) } \\
36,37,43\end{array}$ & $\begin{array}{l}\mathrm{NCI} \text { and NC2 of type VII } \\
\text { collagen (inciting factor), } \\
\text { laminin 332, laminin } 31 \mathrm{I} \text {, and } \\
\text { BPAGI (result of epitope } \\
\text { spreading?) }\end{array}$ \\
\hline
\end{tabular}

Abbreviations: ACR, American College of Rheumatology; ANA, antinuclear antibodies; ABD, autoimmune subepidermal bullous diseases; BP, bullous pemphigoid; BPAGI (BP230), bullous pemphigoid 230 kDa; BPAG2 (BPI80), bullous pemphigoid antigen 180 kDa; BP-like EBA, Bullous pemphigoid like Epidermolysis Bullosa Acquisita; BSLE, bullous systemic lupus erythematosus; BZM, basement membrane zone; C3, complement component 3; CP, cicatricial pemphigoid; CPBP, Cicatricial Pemphigoid type Brunsting Perry; DH, dermatitis herpetiformis; DIF, direct immunofluorescence; EBA, epidermolysis bullosa acquisita; ELISA, enzyme-linked immunosorbent assay; EULAR, european league against rheumatism; Floor pattern, dermal side of the blister in IIF using IM NaCl-split skin (SSS) as a substrate; IIF, indirect immunofluorescence; IgA, Immunoglobulin A; IgG, Immunoglobulin G; IgM, immunoglobulin M; IgA-EBA, Immunoglobulin A Epidermolysis Bullosa Acquisita; LAD, Linear IgA Dermatosis; LAD-I, a 120 kDa truncated domain of BPAG2; MMP, mucous membrane pemphigoid; MM-EBA, Mucous Membrane- Epidermolysis Bullosa Acquisita; $\mathrm{NCl}$, non-collagenous domain type I; NC2, non-collagenous domain type 2; NCI6a, N-terminal non-collagenous 16 domain; Roof pattern, epidermal side of the blister in IIF using I M NaCl-split skin (SSS) as a substrate; SLICC, Systemic Lupus Erythematosus International Collaborating Clinics. 
immunosuppressive therapy may be warranted due to the risk of disease progression leading to the serious complications, such as blindness, airway obstruction, or esophageal stricture, as well as for preventing atrophic scars and scarring alopecia. $^{5,13}$

There is no validated therapeutic approach for BPMMP. In general, BPMMP limited to the oral cavity is rather considered as a mild blistering disorder and usually responsive to anti-inflammatory treatment only. Topical high potency glucocorticosteroids have been suggested as a first-line option by some authors. ${ }^{23}$ Successful therapy with topical tacrolimus has also been described. ${ }^{35}$ However, patients with involvement in different areas require more aggressive therapy containing prednisone plus dapsone or other immunosuppressive drugs, ie azathioprine and low-dose methotrexate. In some cases, anti-inflammatory agents are successful, like tetracycline (1-2 g/day), doxycycline, nicotinic acid, and colchicine. ${ }^{11,14}$ Successful treatment of severe BPMMP with rituximab has also been reported. ${ }^{39}$ It may be hypothesized that the response to treatment depends on the targeted antigens and the level of the subepidermal split; however, further studies are requisite on this item.

The current patient responded well to standard 3-months therapy with oral prednisone for an initial dose of $30 \mathrm{mg} / \mathrm{day}$ along with dapsone $(50 \mathrm{mg} /$ day $)$ and remained free of relapses on the maintained dose of prednisone $(5 \mathrm{mg} /$ day $)$ during the 5-months follow-up. In a recent review by Osipowicz et al, a combination of prednisone and dapsone was the most commonly used scheme, but there were also $33 \%$ of good responses to dapsone monotherapy, while $14 \%$ of patients with BPMMP responded well to prednisone alone. ${ }^{11}$

\section{Conclusion}

The presented case can be considered as a rare Brunsting-Perry type of MMP. Currently, CPBP is considered to be a separate type of autoimmune blistering disorder with a predilection to the upper part of the body involvement, and recently, it has been more precisely characterized from other autoimmune subepidermal bullous disorders. However, unspecific or polymorphic clinical presentation and immunological heterogeneity may underly the long diagnostic delay. It should be considered each time in differentiating localized blistering lesions of the upper part of the body, including BP, MMP, EBA, LABD, and BSLE, that may mimic each other, especially at the onset of the disease, but they differ in the course, prognosis, and response to treatment. Our patient presented clinical features most similar to localized EBA, but serum studies failed to detect circulating antibodies. However, the final diagnosis of BPMMP was confirmed by the LCSM study. This technique may represent a helpful tool for accurate differential diagnosis of autoimmune subepidermal blistering disorders, in particular when circulating antibodies are not detectable. Quick diagnosis and proper treatment in the presented case were essential in order to avoid disfigurement of cosmetically important areas in this young female.

\section{Ethics and Consent}

Ethical approval for this study was obtained from the Ethics Committee of the Medical University of Warsaw, Poland $(\mathrm{KB} / 118 / 2005)$. The patient provided informed consent for the case details and images to be published.

\section{Acknowledgments}

This work was supported by a grant from the National Center for Science, Poland (no. N N402 661940).

\section{Disclosure}

The authors report no conflicts of interest in this work.

\section{References}

1. Nguyen Q, Foster CS. Cicatricial pemphigoid: diagnosis and treatment. Int Ophthalmol Clin. 1996;36(1):41-60. doi:10.1097/00004397-19960361000007

2. Buonavoglia A, Leone P, Dammacco R, et al. Pemphigus and mucous membrane pemphigoid: an update from diagnosis to therapy. Autoimmun Rev. 2019;18(4):349-358. doi:10.1016/j.autrev.2019.02.005

3. Ayvaz H, Gönül M, Atay S. Bullous Systemic Lupus Erythematosus and Cicatricial Pemphigoid. Intechopen; 2018. doi:10.5772/intechopen.74069

4. Garcia-Martin P, Franga J, Hashimoto T, et al. Brunsting-Perry-type cicatricial pemphigoid with IgG autoantibodies to LAD-1. Br J Dermatol. 2014;170:735-758. doi:10.1111/bjd.12677 
5. Daniel DS, Murrel DF. Review of autoimmune blistering diseases: the Pemphigoid diseases. J Eur Acad Dermatol Venerol. 2019;33(9):1685-1694. doi:10.1111/jdv.15679

6. Sato-Shibuya M, Dainichi T, Egawa G, et al. Case with Brunsting-Perry-like localized subepidermal blister formations and immunoglobulin G antibodies against unidentified basement membrane zone antigen. J Dermatol. 2016;43:426-428. doi:10.1111/1346-8138.13084

7. Contestable JJ, Edhegard KD, Meyerle JH. Bullous systemic lupus erythematosus: a review and update to diagnosis and treatment. Am J Clin Dermatol. 2014;15:517-524. doi:10.1007/s40257-014-0098-0

8. Brunsting LA, Perry HO. Benign Pemphigoid? A report of seven cases with chronic, scarring, herpetiform plaques about the head and neck. $A M A$ Arch Derm. 1957;75(4):489-501. doi:10.1001/archderm.1957.01550160015002

9. Graham JH, MacVicar DN. Bullous dermatosis. In: Graham JH, Johnson WC, Helwig EF, editors. Dermal Pathology. Hagerstown, Md: Harper \& Row Publishers Inc; 1972:269-323.

10. Leenutaphong V, von Kries R, Plewig G. Localized cicatricial pemphigoid (Brunsting-Perry): electron microscopic study. J Am Acad Dermatol. 1989;21:1089-1093. doi:10.1016/S0190-9622(89)70302-9

11. Osipowicz K, Jakubowska B, Kowalewski C, Hashimoto T, Wozniak K. Laser scanning confocal microscopy for diagnostics of Brunsting-Perry type cicatricial pemphigoid cases, along with review of literature. J Clin Exp Dermatol Res. 2019;10:479.

12. Michel B, Bean SF, Chorzelski T, Fedele CF. Cicatricial pemphigoid of Brunsting-Perry: immunofluorescent studies. Arch Dermatol. 1977;113:1403-1405. doi:10.1001/archderm.1977.01640100081015

13. Chan LS, Ahmed AR, Anhalt GJ, et al. The first international consensus on mucous membrane pemphigoid: definition, diagnostic criteria, pathogenic factors, medical treatment, and prognostic indicators. Arch Dermatol. 2002;138:370-379. doi:10.1001/archderm.138.3.370

14. Imstepf V, Cazzaniga S, Beltraminelli H, Borradori L, Feldmeyer L. Brunsting-Perry pemphigoid: a retrospective case series of a frequently unrecognized condition. J Am Acad Dermatol. 2020;20:S0190-9622(20)32841-3.

15. Jedlickova H, Niedermeier A, Zgazrova S, et al. Brunsting-Perry pemphigoid of the scalp with antibodies against laminin 332 . Dermatology. 2011;222:193-195. doi:10.1159/000322842

16. Iranzo P, Herrero C, Castro J, et al. Penfigoide cicatrizal de Brunsting-Perry. Actas Dermo-Sif. 1979;70:430-434.

17. Walling HW, Sontheimer RD. Cutaneous lupus erythematosus: issues in diagnosis and treatment. Am J Clin Dermatol. 2009;10:365-381. doi: $10.2165 / 11310780-000000000-00000$

18. Reis Gavazzoni Dias M, Vilar Gedes Aparecid E, Beneto de Oliviera C, et al. Brunsting-Perry type pemphigoid causing secondary cicatricial alopecia in 2 patients. Skin Appendage Disord. 2018;4(4):308-311. doi:10.1159/000485570

19. Martín JM, Pinazo I, Molina I, et al. Cicatricial pemphigoid of the Brunsting-Perry type. Int J Dermatol. 2009;48:293-294. doi:10.1111/j.13654632.2009.03975.x

20. Takeichi S, Kubo Y, Arase S, Hashimoto T, Ansai S. Brunsting-Perry type localized bullous pemphigoid, possibly induced by furosemide administration and sun exposure. Eur J Dermatology. 2009;19:500-503. doi:10.1684/ejd.2009.0715

21. Woźniak K, Kazama T, Kowalewski C. A practical technique for differentiation of subepidermal bullous diseases: localization of in vivo bound IgG by laser scanning confocal microscopy. Arch Dermatol. 2003;139:1007-1011. doi:10.1001/archderm.139.8.1007

22. Sugita Y, Inomata N, Takahashi Y, et al. Autoimmune vesicles on the face and neck. A variant of Brunsting-Perry type localized bullous pemphigoid? Eur J Dermatol. 2001;11:557-559.

23. Minato H, Ishii N, Fukuda S, et al. Heterogeneity of Brunsting-Perry type pemphigoid: a case showing blister formation at the lamina lucida, immune deposition beneath the lamina densa and autoantibodies against the 290-kD polypeptide along the lamina densa. J Dermatol. 2011;38:887892. doi:10.1111/j.1346-8138.2010.01172.x

24. Person JR, Rogers RS, Perry HO. Localized pemphigoid. Br J Dermatol. 1976;95:531-534. doi:10.1111/j.1365-2133.1976.tb00864.x

25. Kamaguchi M, Iwata H. The diagnosis and blistering mechanisms of mucous membrane pemphigoid. Front Immunol. 2019;10:34. doi:10.3389/ fimmu.2019.00034

26. Fukuda S, Tsuruta D, Uchiyama M, et al. Brunsting-Perry type pemphigoid with IgG autoantibodies to laminin-332, BP230 and desmoplakins I/II. Br J Dermatol. 2011;165:433-435. doi:10.1111/j.1365-2133.2011.10343.x

27. Daito J, Katoh N, Asai J, et al. Brunsting-Perry cicatricial pemphigoid associated with autoantibodies to the C-terminal domain of BP180. $B r J$ Dermatol. 2008;159:984-986. doi:10.1111/j.1365-2133.2008.08753.x

28. Tanaka N, Dainichi T, Ohyama B, et al. A case of epidermolysis bullosa acquisita with clinical features of Brunsting-Perry pemphigoid showing an excellent response to colchicine. J Am Acad Dermatol. 2009;61(4):715-719. doi:10.1016/j.jaad.2008.12.020

29. Joly P, Ruto F, Thomine E, et al. Brunsting-Perry cicatricial bullous pemphigoid: a clinical variant of localized acquired epidermolysis bullosa? $J$ Am Dermatol. 1993;28(1):89-92

30. Asfour L, Chong H, Mee J, Groves R, Singh M. Epidermolysis bullosa acquisita (Brunsting-Perry Pemphigoid variant) localized to the face and diagnosed with antigen identification using skin deficient in type VII collagen. Am J Dermatopathol. 2017;39:90-96. doi:10.1097/ DAD.0000000000000829

31. Lee CW, Jun KM. Epidermolysis bullosa acquisita presenting with localized facial blisters. Clin Exp Dermatol. 1992;17:363-365. doi:10.1111/ j.1365-2230.1992.tb00234.x

32. Kurzhals G, Stolz W, Meurer M, Kunze J, Kreig T. Acquired epidermolysis bullosa with the clinical features of Brunsting-Perry cicatricial bullous pemphigoid. Arch Dermatol. 1991;127:391-395. doi:10.1001/archderm.1991.01680030111016

33. Murata Y, Tani M, Kumano K. Localized chronic pemphigoid of Brunsting-Perry ultrastructural localization of IgG and complement components. Arch Dermatol. 1983;119:921-924. doi:10.1001/archderm.1983.01650350049014

34. Choi GS, Lee E-S, Ch-S K, Lee S. Epidermolysis bullosa acquisita localized to the face. J Dermatol. 1998;25:19-22. doi:10.1111/j.13468138.1998.tb02339.x

35. Demitsu T, Kakurai M, Yoneda K, et al. Localized pemphigoid (Brunsting-Perry type) with IgG antibody to BP180 NC16a domain resembling lupus erythematosus successfully treated with topical tacrolimus therapy. J Eur Acad Dermatol Venereol. 2009;23:79-80. doi:10.1111/j.14683083.2008.02702.x

36. Vico-Alonso C, Palencia-Perez S. Linear IgA bullous dermatosis. N Engl J Med. 2020;382(23):2248. doi:10.1056/NEJMicm1913412

37. Lammer J, Hein R, Roenneberg S, et al. Drug-induced linear IgA bullous dermatosis: a case report and review of the literature. Acta Derm Venerolog. 2019;99(6):508-515. doi:10.2340/00015555-3154 
38. Diaz MS, Morita L, Ferrari B, et al. Linear IgA bullous dermatosis: a series of 17 cases. Actas dermo-sifiliograficas. 2019;110(8):673-680. doi:10.1016/j.ad.2018.06.017

39. Li Y, Foshee JB, Sontheimer RD. Sustained clinical response to rituximab in a case of life-threatening overlap subepidermal autoimmune blistering disease. J Am Acad Dermatol. 2011;64(4):773-778. doi:10.1016/j.jaad.2009.09.045

40. Vorobyev A, Ludwig R, Schmidt E. Clinical features and diagnosis of epidermolysis bullosa simplex. Expert Rev Clin Immunol. 2017;13(2):157169. doi:10.1080/1744666X.2016.1221343

41. Koga H, Prost-Squarcioni C, Iwata H. Epidermolysis bullosa acquisita: the 2019 update. Front Med. 2019;5:362.

42. Rutin S, Chanprapaph K. Vesiculobullous diseases in relation to lupus erythematosus. Clin Cosmet Invest Dermatol. 2019;12:653-667. doi: $10.2147 /$ CCID.S220906

43. Bernett CN, Fong M, Rosario-Collazo JA. Linear IGA dermatosis. In: StatPearls. Treasure Island (FL): StatPearls Publishing; 2021.

Clinical, Cosmetic and Investigational Dermatology

\section{Publish your work in this journal}

Clinical, Cosmetic and Investigational Dermatology is an international, peer-reviewed, open access, online journal that focuses on the latest clinical and experimental research in all aspects of skin disease and cosmetic interventions. This journal is indexed on CAS. The manuscript management system is completely online and includes a very quick and fair peer-review system, which is all easy to use. Visit http://www. dovepress.com/testimonials.php to read real quotes from published authors.

Submit your manuscript here: https://www.dovepress.com/clinical-cosmetic-and-investigational-dermatology-journal 